\title{
Indoor Cooking Practices and Associated Health Factors Among Participants in the Dominican Republic and Nicaragua: A Collaborative Study Between Respiratory Therapy Students and Comunidad Connect
}

\author{
Rachel Culbreth \\ Georgia State University, rculbreth@gsu.edu \\ Rachel Trawick \\ Georgia State University, rtrawick2@gsu.edu \\ Jon Thompson \\ Comunidad Connect, jon@comunidadconnect.org \\ Douglas S. Gardenhire \\ Georgia State University, dgardenhire@gsu.edu
}

Follow this and additional works at: https://nsuworks.nova.edu/ijahsp

Part of the Community Health and Preventive Medicine Commons, Environmental Public Health Commons, Environmental Studies Commons, and the Epidemiology Commons

\begin{abstract}
Recommended Citation
Culbreth R, Trawick R, Thompson J, Gardenhire DS. Indoor Cooking Practices and Associated Health Factors Among Participants in the Dominican Republic and Nicaragua: A Collaborative Study Between Respiratory Therapy Students and Comunidad Connect. The Internet Journal of Allied Health Sciences and Practice. 2021 Jan 01;19(3), Article 18.
\end{abstract}

This Manuscript is brought to you for free and open access by the College of Health Care Sciences at NSUWorks. It has been accepted for inclusion in Internet Journal of Allied Health Sciences and Practice by an authorized editor of NSUWorks. For more information, please contact nsuworks@nova.edu. 


\title{
Indoor Cooking Practices and Associated Health Factors Among Participants in the Dominican Republic and Nicaragua: A Collaborative Study Between Respiratory Therapy Students and Comunidad Connect
}

\begin{abstract}
The purpose of this study is to determine factors associated with indoor cooking practices and specific vital signs across two middle-income countries, Dominican Republic and Nicaragua. This study used data from Nicaragua ( $n=76)$ and Dominican Republic $(n=62)$ (collected in 2018-2019). Multivariable linear regression was utilized to determine factors associated with carbon monoxide levels and systolic blood pressure. Among all participants $(n=138)$, approximately half lived in Nicaragua $(n=76,55.1 \%)$ and half lived in Dominican Republic $(n=62,44.9 \%)$. The overall smoking prevalence in each country was low $(9.2 \%$ in Nicaragua and $4.8 \%$ in Dominican Republic). Age was associated with higher carbon monoxide levels and higher systolic blood pressure measurements in each country. Future studies should examine a broader range of contextual and behavioral factors related to carbon monoxide and peak flow measurements in the two countries.
\end{abstract}

\section{Author Bio(s)}

Rachel Culbreth, PhD, MPH, RRT, is an Assistant Professor in the Department of Respiratory Therapy at Georgia State University in Atlanta, GA.

Rachel Trawick, MS, RRT, is a licensed Respiratory Therapist and previous Graduate Teaching Assistant at Georgia State University.

Jon Thompson, MSW, is the director of Comunidad Connect, a non-profit organization that provides housing stability, improved healthcare access, and youth programs to individuals in rural communities in the Dominican Republic and Nicaragua.

Douglas S. Gardenhire, EdD, RRT, RRT-NPS, FAARC, is the Chair of the Department of Respiratory Therapy, Governor's Teaching Fellow, and Clinical Professor at Georgia State University. 


\title{
TIAHSP \\ The Internet Joumnal of Allied Health Sciences and Practice \\ Vol. 19 No. 3 ISSN 1540-580X
}

\section{Indoor Cooking Practices and Associated Health Factors Among Participants in the Dominican Republic and Nicaragua: A Collaborative Study Between Respiratory Therapy Students and Comunidad Connect}

\author{
Rachel Culbreth ${ }^{1}$ \\ Rachel Trawick ${ }^{1}$ \\ John Thompson² \\ Douglas S. Gardenhire ${ }^{1}$ \\ 1. Georgia State University \\ 2. Comunidad Connect \\ United States
}

\begin{abstract}
The purpose of this study is to determine factors associated with indoor cooking practices and specific vital signs across two middle-income countries, Dominican Republic and Nicaragua. This study used data from Nicaragua $(n=76)$ and Dominican Republic ( $\mathrm{n}=62$ ) (collected in 2018-2019). Multivariable linear regression was utilized to determine factors associated with carbon monoxide levels and systolic blood pressure. Among all participants ( $n=138)$, approximately half lived in Nicaragua $(n=76,55.1 \%)$ and half lived in Dominican Republic $(n=62,44.9 \%)$. The overall smoking prevalence in each country was low (9.2\% in Nicaragua and $4.8 \%$ in Dominican Republic). Age was associated with higher carbon monoxide levels and higher systolic blood pressure measurements in each country. Future studies should examine a broader range of contextual and behavioral factors related to carbon monoxide and peak flow measurements in the two countries.
\end{abstract}

Keywords: indoor air pollution, hypertension, community health, carbon monoxide, environmental health 


\section{INTRODUCTION}

Indoor cooking practices utilizing biomasses, such as wood or coal stoves, are a common practice in lower and middle income countries (LMICs) and an urgent public health crisis. ${ }^{1-3}$ Exposure to indoor biomass pollution has been linked to chronic obstructive pulmonary disorder (COPD), mortality, stroke, ischemic heart disease, and lung cancer. ${ }^{3,4}$ Additionally, nearly 4 million deaths are attributable to indoor cooking practices each year. ${ }^{4}$ Approximately $50 \%$ of pediatric deaths from pneumonia are attributable to indoor cooking practices and indoor air pollution. ${ }^{4}$ Additionally, children exposed to indoor air pollution are more likely to develop acute lower respiratory infections and sleep-disordered breathing. 5,6

Women may be particularly susceptible to indoor air pollution and indoor cooking practice. ${ }^{3}$ One previous review found an elevated risk of being diagnosed with COPD for women who utilized indoor cooking practices (pooled OR: 1.38; 95\% Cl: 1.28, 1.57). ${ }^{3}$ There is also evidence linking breast cancer risk, adverse pregnancy outcomes, and cataracts with indoor wood burning stoves and fireplaces. 7,8

In the Caribbean nations, such as in the Dominican Republic and Nicaragua, indoor cooking practices with biomass fuels are common. ${ }^{1,5,9}$ Previous research in Nicaragua showed that obese participants experienced an elevated systolic blood pressure that corresponded with higher fine particulate matter concentrations. ${ }^{9}$ This is particularly relevant for the nation of Nicaragua, where cardiovascular disease is the leading cause of death. ${ }^{10}$

Multiple studies have found that improved cook stoves, including ones that are located outside, with alternative fuel material, and/or with a ventilation pipe connecting to the outdoors, lower indoor air pollution and ultimately, may influence the comorbidity and mortality associated with indoor air pollution. ${ }^{11,12}$ Thakur and colleagues found that among all studies included in their review, women experienced a reduction in respiratory and COPD symptoms from improved cookstoves; however, children experienced no statistically significant benefit. ${ }^{12}$

While a strong association has been established between indoor cooking practices and adverse health conditions, few studies have examined the context of indoor cooking practices in the Caribbean nations, such as the Dominican Republic and Nicaragua. ${ }^{1,5,9}$ Furthermore, the cardiovascular impact of fine particle pollution indoors has traditionally been measured using blood pressure measurements. However, this study proposes examining the impact of indoor air pollution using alternative anthropometric measures (measured oxygen saturation, carbon monoxide (CO) measurements, heart rate, peak flow and respiratory rate). These anthropometric measurements were obtained from a unique collaboration between both respiratory therapy students and community health workers. Our hypotheses are that indoor cookstoves using biomass fuel will be associated with higher carbon monoxide measurements, elevated heart rate and respiratory rate, lower oxygen saturation measurements, and reduced peak flow measurements. Additionally, we hypothesize that females will have higher systolic blood pressure measurements and higher carbon monoxide measurements due to their hypothesized elevated exposure to indoor air pollution.

\section{METHODS}

\section{Institutional Review Board Approval}

Georgia State University Institutional Review Board approved this study. The authors have no conflicts of interest, and no funding was received for this study. All procedures performed in this study were in accordance with the ethical standards of the University Institutional Review Board and with the 1964 Helsinki Declaration and its later amendments or comparable ethical standards. Informed consent was obtained from all individual participants included in the study. Informed consent was obtained in the language preferred by the participants, in either Spanish or English.

\section{Participants}

Participants were randomly selected from households in rural villages in two countries, Nicaragua $(n=76)$ and Dominican Republic ( $\mathrm{n}=62$ ). Participants were approached by university students participating in a study abroad trip and personnel of Comunidad Connect. Individual participants gave verbal informed consent for the study.

\section{Setting}

This study was conducted in 2018-2019 in rural villages in both Dominican Republic (2019) and Nicaragua (2018), specifically in regions that Comunidad Connect serves. Comunidad Connect is a non-profit organization that serves rural, underserved populations in the Caribbean and Central America. Comunidad Connect seeks to improve the health and social well-being of rural individuals by connecting communities to accessible healthcare, improving families' indoor air pollution through ventilated and outdoor cookstoves, and providing health education for families.

\section{Assessments/Survey Instruments}

Brief cross-sectional surveys were conducted among participants and included questions on demographics (age, sex, and village name), smoking history, and a brief health history. Stove descriptions were documented by the study personnel (characterized by improved stoves with ventilation pipe, improved outdoor stoves, or indoor stoves without ventilation pipes). 
Respiratory therapy students and study personnel obtained anthropometric measurements from participants (heart rate, blood pressure, $\mathrm{SpO} 2$, and peak flow measurements). Respiratory therapy students received training in obtaining these anthropometric measurements in clinical and laboratory classroom instruction, in addition to training in the field. Study personnel were also thoroughly trained on these anthropometric measurements by experienced clinical faculty prior to data collection. No complications were noted from the study.

\section{Statistical Analysis}

Descriptive statistics were computed among demographic, environmental, and behavioral characteristics across the two countries. Additionally, chi-square tests and independent samples t-tests were conducted to determine statistically significant differences between the two countries. Multiple linear regression analyses were conducted to obtain adjusted estimates for predictors for two outcomes: 1) $\mathrm{CO}$ and 2) systolic blood pressure. Predictors included age, gender, stove characteristics, and cigarette smoking behavior. All analyses were conducted using SAS 9.4 (Cary, NC).

\section{RESULTS}

Among all participants $(n=138)$, approximately half lived in Nicaragua $(n=76,55.1 \%)$ and half lived in Dominican Republic $(n=62,44.9 \%)$ (Table 1). The ages of the participants in the Dominican Republic were slightly older than the ages of participants in Nicaragua (46.9 vs. 32.9, respectively), which was also statistically significant ( $p=0.0002)$. A higher percentage of Dominican Republic participants reported using an inside cook stove (55.4\%) compared to Nicaraguan participants (11.8\%), which was statistically significant $(p<0.0001)$. The overall smoking prevalence in each country was relatively low; however, Nicaragua's smoking prevalence was slightly higher $(9.2 \%)$ than Dominican Republic $(4.8 \%)$. There were no statistically significant differences in blood pressure, but there were statistically significant differences in $\mathrm{SpO} 2$ measurements between Nicaragua and Dominican Republic ( $98.3 \%$ vs. $99.4 \%$, respectively). While these were statistically significant, these two measurements were not clinically significant. Finally, there were statistically significant differences in peak flow measurements, with Nicaraguan participants having a lower mean peak flow $(260.6 \mathrm{~L} / \mathrm{min})$ compared to Dominican Republic participants (327.4 L/min). No differences were found between carbon monoxide levels.

Table 1. Descriptive statistics of demographic and behavioral characteristics among participants in Nicaragua and Dominican Republic ( $\mathrm{n}=138)$

\begin{tabular}{|c|c|c|c|c|}
\hline & $\begin{array}{l}\text { Nicaragua } \\
\text { participants } \\
(\mathrm{n}=76,55.1 \%)\end{array}$ & $\begin{array}{l}\text { Dominican } \\
\text { Republic } \\
\text { participants } \\
(\mathrm{n}=62,44.9 \%)\end{array}$ & $\begin{array}{l}\text { Chi-Square, (df), } \\
\text { p-value }\end{array}$ & $\begin{array}{l}\text { T-test, (df), p- } \\
\text { value }\end{array}$ \\
\hline \multicolumn{5}{|l|}{ Gender } \\
\hline Male & $24(31.6 \%)$ & $25(41.0 \%)$ & $0.001,(1)$ & --- \\
\hline Female & $35(46.1 \%)$ & $36(59.0 \%)$ & $p=0.97$ & \\
\hline Age, mean (SD) & $32.9(26.1)$ & $46.9(16.7)$ & -- & $\begin{array}{l}-3.81,(129.31), \\
p=0.0002\end{array}$ \\
\hline \multicolumn{5}{|l|}{ Cook stove location } \\
\hline $\begin{array}{l}\text { Outside/stove with pipe } \\
\text { Inside }\end{array}$ & $\begin{array}{l}67(88.2 \%) \\
9(11.8 \%)\end{array}$ & $\begin{array}{l}25(44.6 \%) \\
31(55.4 \%)\end{array}$ & $\begin{array}{l}28.9,(1) \\
p<0.001\end{array}$ & --- \\
\hline \multicolumn{5}{|l|}{ Currently smokes } \\
\hline $\begin{array}{l}\text { Yes } \\
\text { No }\end{array}$ & $\begin{array}{l}7(9.2 \%) \\
69(90.8 \%)\end{array}$ & $\begin{array}{l}3(4.8 \%) \\
59(95.2 \%)\end{array}$ & $0.51^{*}$ & --- \\
\hline \multicolumn{5}{|l|}{ Last visit to health clinic } \\
\hline Less than one month ago & $25(32.9 \%)$ & $19(30.7 \%)$ & $9.22,(4), p=0.06$ & --- \\
\hline Between 1-6 months & $23(30.3 \%)$ & $19(30.7 \%)$ & & \\
\hline Between 6 months and 1 year & $1(1.3 \%)$ & $10(16.1 \%)$ & & \\
\hline Over a year ago & $9(11.8 \%)$ & $13(21.0 \%)$ & & \\
\hline Never & $1(1.3 \%)$ & $1(1.6 \%)$ & & \\
\hline Heart Rate, mean (SD) & $87.8(17.5)$ & $78.2(10.8)$ & --- & $\begin{array}{l}3.79,(110.82) \\
p=0.0002\end{array}$ \\
\hline Blood pressure systolic, mean (SD) & $128.1(17.5)$ & $130.5(20.3)$ & --- & $\begin{array}{l}-0.64,(109) \\
p=0.52\end{array}$ \\
\hline Blood pressure diastolic, mean (SD) & $77.8(11.0)$ & $79.2(13.0)$ & --- & $\begin{array}{l}-0.60,(109) \\
p=0.55\end{array}$ \\
\hline SpO2, mean (SD) & $98.3(2.2)$ & $99.4(0.8)$ & --- & $\begin{array}{l}-3.94,(82.14) \\
p=0.0002\end{array}$ \\
\hline Carbon Monoxide \%, mean (SD) & $3.5(2.8)$ & $4.24(2.30)$ & --- & $\begin{array}{l}-1.63,(127) \\
p=0.11\end{array}$ \\
\hline
\end{tabular}




\begin{tabular}{|c|c|c|c|c|}
\hline Peak Flow (L/min), mean (SD) & $260.6(92.6)$ & $327.4(132.9)$ & --- & $\begin{array}{l}-3.17,(107.48) \\
p=0.0020\end{array}$ \\
\hline
\end{tabular}

In the adjusted model for carbon monoxide levels among participants in Nicaragua (Table 2), age was associated with higher carbon monoxide levels ( $E s t: 0.05, \mathrm{SE}=0.01, p=0.0001$ ). On average, each additional year of age corresponded with a 0.05 $\mathrm{mmHg}$ positive difference in carbon monoxide levels. Females had statistically significant lower carbon monoxide levels than males, which resulted in an estimated $1.44 \%$ lower carbon monoxide level among females compared to males, on average. Age and gender were the only statistically significant predictors for carbon monoxide levels in Nicaragua. Age, gender, stove characteristics, and smoking explained $30 \%$ of the variation in carbon monoxide levels in Nicaragua $\left(R^{2}=0.30\right)$.

Table 2. Adjusted estimates of predictors associated with carbon monoxide levels among participants living in Nicaragua $(\mathrm{n}=76)$

\begin{tabular}{llll} 
& Estimate & $S E$ & $P$-value \\
\hline Intercept & 2.24 & 0.67 & $\mathbf{0 . 0 0 1 6}$ \\
Age & 0.05 & 0.01 & $\mathbf{0 . 0 0 0 1}$ \\
Gender (females vs. males) & -1.44 & 0.63 & $\mathbf{0 . 0 3}$ \\
Stove with pipe & 0.47 & 0.87 & 0.59 \\
Smoke cigarettes & 0.09 & 1.16 & 0.93 \\
\hline Note. $\mathrm{R}^{2}=30 ; \mathrm{F}(4)=5.29, p=001 ;$ Root MSE: 221 & &
\end{tabular}

Note. $\mathrm{R}^{2}=.30 ; F(4)=5.29, p=.001$; Root MSE: 2.21 .

For the systolic blood pressure model, age was the only statistically significant predictor for systolic blood pressure among participants in Nicaragua (Table 3). On average, each additional year of age corresponded with a $0.41 \mathrm{mmHg}$ difference in systolic blood pressure ( $p=0.0002$ ). Also, a 10 -year difference in age corresponds to a $4.1 \mathrm{mmHg}$ difference in systolic blood pressure. While gender was not statistically significant, on average, females had lower systolic blood pressure (Est: -6.71 $\mathrm{mmHg})$ compared to males $(\mathrm{p}=0.17)$. Age, gender, stove characteristics, and smoking explained $37 \%$ of the variation in systolic blood pressure among participants in Nicaragua $\left(R^{2}=0.37\right)$.

Table 3. Adjusted estimates of predictors associated with systolic blood pressure levels among participants living in Nicaragua $(\mathrm{n}=76)$

\begin{tabular}{llll} 
& Estimate & $S E$ & $P$-value \\
\hline Intercept & 116.45 & 5.85 & $<0.001$ \\
Age & 0.41 & 0.10 & $\mathbf{0 . 0 0 0 2}$ \\
Gender (females vs. males) & -6.71 & 4.80 & 0.17 \\
Stove with pipe & -8.14 & 7.22 & 0.27 \\
Smoke cigarettes & -10.94 & 7.93 & 0.18 \\
\hline Note. $R^{2}=37 ; F(4)=5.61, p=.001 ;$ Root MSE: 14.91. & &
\end{tabular}

In the adjusted model for carbon monoxide levels among participants in the Dominican Republic (Table 4), no predictors (age, gender, stove characteristics or smoking) were statistically significant in this model. However, for the systolic blood pressure model (Table 5) among participants in the Dominican Republic, age was statistically significantly associated with higher systolic blood pressure levels. On average, each additional year of age corresponded to a $0.60 \mathrm{mmHg}$ difference in systolic blood pressure ( $p=0.0013)$. Alternatively, each 10 -year age difference corresponds to a $6 \mathrm{mmHg}$ difference in systolic blood pressure. While gender was not statistically significant in the systolic blood pressure model, on average, females had higher systolic blood pressure levels compared to males (Est: $6.65 \mathrm{mmHg}$ ). Age, gender, cook stove characteristics, and cigarette smoking accounted for $23 \%$ of the variation in systolic blood pressure levels among participants living in the Dominican Republic.

Table 4. Adjusted estimates of predictors associated with carbon monoxide levels among participants living in Dominican Republic ( $n=62)$

\begin{tabular}{llll} 
& Estimate & $S E$ & $P$-value \\
\hline Intercept & 4.57 & 1.33 & 0.001 \\
Age & 0.01 & 0.02 & 0.59 \\
Gender (females vs. males) & -0.41 & 0.73 & 0.58 \\
Wood or coal stove & -1.09 & 0.79 & 0.18 \\
Cook stove location & 0.25 & 0.74 & 0.74 \\
Smoke cigarettes & 0.07 & 1.56 & 0.97 \\
\hline
\end{tabular}

Note. $\mathrm{R}^{2}=.08 ; F(5)=5.29, p=.51 ;$ Root MSE: 2.40 . 
Table 5. Adjusted estimates of predictors associated with systolic blood pressure levels among participants living in Dominican Republic ( $\mathrm{n}=62)$

\begin{tabular}{llll} 
& Estimate & $S E$ & $P$-value \\
\hline Intercept & 101.86 & 11.29 & $<0.001$ \\
Age & 0.60 & 0.18 & $\mathbf{0 . 0 0 1 3}$ \\
Gender (females vs. males) & 6.65 & 5.98 & 0.27 \\
Wood or coal stove & -6.43 & 6.46 & 0.32 \\
Cook stove location & 0.63 & 6.01 & 0.91 \\
Smoke cigarettes & 3.22 & 12.68 & 0.80 \\
\hline
\end{tabular}

Note. $\mathrm{R}^{2}=.23 ; F(5)=2.89, p=0.02 ;$ Root MSE: 19.57

\section{DISCUSSION}

This study presents important findings on indoor cooking practices and associated anthropometric and behavioral factors in two middle-income nations: Dominican Republic and Nicaragua. Differences between indoor cooking practices, peak flow measurements, average heart rate, and SpO2 measurements were found between Nicaragua and Dominican Republic participants. Future studies should examine a broader range of contextual and behavioral factors associated with the variation in peak flow measurements, average heart rate, and $\mathrm{SpO} 2$ measurements in the two countries. Additionally, cook stove characteristics vary widely between communities and countries, further emphasizing the need to develop tailored prevention interventions. $1,12,13$

In our adjusted models, age and being male were predictors of higher carbon monoxide levels in Nicaragua. However, the higher carbon monoxide level among males compared to females was contradicting to our previous hypothesis. Women traditionally perform the majority of the cooking duties, which includes the utilization of indoor cook stoves and subsequently exposure to indoor air pollution, which would theoretically yield higher carbon monoxide levels. ${ }^{14}$ Many studies examining improved cookstoves have only focused on women, as women are traditionally responsible for the cooking duties in many rural Caribbean communities. ${ }^{15}$ However, there may be other reasons why males had higher carbon monoxide levels than females among Nicaraguan participants in this study. It's possible that a higher percentage of men smoked cigarettes in the sample among Nicaraguan participants. While we had a very small sample of people reporting smoking $(n=7)$, the majority $(n=4)$ were males ( $n=2$ females, $n=1$ unreported gender). It's also possible that some men are responsible for cooking in certain households, which also could partially explain our finding. Future research should investigate the interactions between smoking and indoor air pollution in this population, specifically pertaining to gender differences in order to critically inform interventions.

Unsurprisingly, older age was associated with higher systolic blood pressure in both Nicaragua and the Dominican Republic. While the estimates for each additional age were small, the estimates actually corresponded to a large difference in systolic blood pressure measurements for 10 years of age. Additionally, while gender was not statistically significant in either model, there were striking differences between the countries. Females in Nicaragua had, on average, lower systolic blood pressure compared to males; whereas females in the Dominican Republic had higher systolic blood pressure levels compared to males. These differences should be explored in future studies to identify the variation in cooking practices and behaviors that may affect systolic blood pressure.

While the current study examined participants of all ages, multiple studies have demonstrated associations among children with adverse health outcomes exposed to indoor air pollution.., 12 More research is needed on the age-specific effects of indoor air pollution in order to inform targeted approaches of prevention. Furthermore, children may be especially vulnerable to indoor air pollution and smoke, thus creating long term adverse health benefits as well.5,12

This study found no association between improved cookstoves with carbon monoxide and systolic blood pressure levels. While improved cook stoves have largely demonstrated health benefits in a variety of settings, certain results have been conflicting. ${ }^{11,12,16,17}$ Noonan and colleagues found that air-filter interventions for cookstoves did not improve asthmatic symptoms among children, but the intervention did decrease the amount of indoor air pollution and fine particulate matter..$^{18}$ While the overwhelming consensus is that improved cookstoves have a positive impact on the reduction of health symptoms and smoke exposure, more studies are needed to identify the optimal interventions for specific cultures and regions, as well as increasing the uptake and acceptability of improved cookstoves. ${ }^{17}$

\section{Limitations}

This study has several limitations which should be noted. First, the sample is restricted to two countries in the Caribbean, potentially limiting the generalizability of the results to other countries in this region. Second, the smoking measures relied on self-report, thus subjected to social desirability bias and potentially recall bias. The overall sample is relatively small; however, there are very few studies on these specific regions regarding indoor air pollution and associated factors and vital signs. Data 
was not collected on how long the improved cookstoves were present in the house, thus limiting an examination of time of exposure. We also did not collect data on the duration of stove exposure per day, which may also explain variability in the findings.

\section{CONCLUSIONS}

Indoor air pollution remains a critically important public health problem. Our study found that indoor cooking practices varied across two countries: Dominican Republic and Nicaragua. Our study also found that improved cookstoves are needed in these rural communities. Age was associated with higher systolic blood pressure measurements and higher carbon monoxide levels in both countries. While improved cookstoves were not associated with either systolic blood pressure or carbon monoxide levels in this study, future studies should examine the context and duration of the improved cookstoves in the home to better inform targeted intervention efforts. Additionally, gender differences in cooking responsibilities and indoor cookstove exposure should be explored.

\section{REFERENCES}

1. Clark ML, Bachand AM, Heiderscheidt JM, et al. Impact of a cleaner-burning cookstove intervention on blood pressure in Nicaraguan women. Indoor Air. 2013;23(2):105-114. doi:10.1111/ina.12003

2. Fatmi Z, Coggon D. Coronary heart disease and household air pollution from use of solid fuel: a systematic review. Br Med Bull. 2016;118(1):91-109. doi:10.1093/bmb/ldw015

3. Sana A, Somda SMA, Meda N, Bouland C. Chronic obstructive pulmonary disease associated with biomass fuel use in women: a systematic review and meta-analysis. BMJ Open Respir Res. 2018;5(1):e000246. doi:10.1136/bmjresp2017-000246

4. World Health Organization. Household Air Pollution and Health.; 2018. https://www.who.int/news-room/factsheets/detail/household-air-pollution-and-health

5. Bautista LE, Correa A, Baumgartner J, Breysse P, Matanoski GM. Indoor charcoal smoke and acute respiratory infections in young children in the Dominican Republic. Am J Epidemiol. 2009;169(5):572-580. doi:10.1093/aje/kwn372

6. Tenero L, Piacentini G, Nosetti L, Gasperi E, Piazza M, Zaffanello M. Indoor/outdoor not-voluptuary-habit pollution and sleep-disordered breathing in children: a systematic review. Transl Pediatr. 2017;6(2):104-110. doi:10.21037/tp.2017.03.04

7. White AJ, Sandler DP. Indoor Wood-Burning Stove and Fireplace Use and Breast Cancer in a Prospective Cohort Study. Environ Health Perspect. 2017;125(7):077011. doi:10.1289/EHP827

8. Zuk M, Rojas L, Blanco S, et al. The impact of improved wood-burning stoves on fine particulate matter concentrations in rural Mexican homes. J Expo Sci Environ Epidemiol. 2007;17(3):224-232. doi:10.1038/sj.jes.7500499

9. Clark ML, Bazemore H, Reynolds SJ, et al. A baseline evaluation of traditional cook stove smoke exposures and indicators of cardiovascular and respiratory health among Nicaraguan women. Int J Occup Environ Health. 2011;17(2):113-121. doi:10.1179/107735211799030942

10. PAHO. Health in the Americas. Pan American Health Organization; 2007.

11. Puzzolo E, Pope D, Stanistreet D, Rehfuess EA, Bruce NG. Clean fuels for resource-poor settings: A systematic review of barriers and enablers to adoption and sustained use. Environ Res. 2016;146:218-234. doi:10.1016/j.envres.2016.01.002

12. Thakur M, Nuyts PAW, Boudewijns EA, et al. Impact of improved cookstoves on women's and child health in low and middle income countries: a systematic review and meta-analysis. Thorax. 2018;73(11):1026-1040. doi:10.1136/thoraxjnl-2017-210952

13. Amadeo $B$, Robert $C$, Rondeau $V$, et al. Impact of close-proximity air pollution on lung function in schoolchildren in the French West Indies. BMC Public Health. 2015;15:45. doi:10.1186/s12889-015-1382-5

14. Hubbell AM, Jareczek FJ, Vonnahme L, Hockenberry JM, Buresh C. Smoke exposure among women in Haiti: the case for improved stoves. Glob Public Health. 2013;8(7):822-830. doi:10.1080/17441692.2013.815793

15. Onakomaiya D, Gyamfi J, Iwelunmor J, et al. Implementation of clean cookstove interventions and its effects on blood pressure in low-income and middle-income countries: systematic review. BMJ Open. 2019;9(5). doi:10.1136/bmjopen-2018-026517

16. Patange OS, Ramanathan $\mathrm{N}$, Rehman $\mathrm{IH}$, et al. Reductions in indoor black carbon concentrations from improved biomass stoves in rural India. Environ Sci Technol. 2015;49(7):4749-4756. doi:10.1021/es506208x

17. Pope D, Bruce N, Dherani M, Jagoe K, Rehfuess E. Real-life effectiveness of "improved" stoves and clean fuels in reducing PM2.5 and CO: Systematic review and meta-analysis. Environ Int. 2017;101:7-18. doi:10.1016/j.envint.2017.01.012

18. Noonan CW, Semmens EO, Smith P, et al. Randomized Trial of Interventions to Improve Childhood Asthma in Homes with Wood-burning Stoves. Environ Health Perspect. 2017;125(9):097010. doi:10.1289/EHP849 